\title{
An unusual cause of an elevated hemidiaphragm.
}

\author{
Authors: Margaret TH Nguyen BMedSci(Hons) MD, Fiona SW Reid BMBS BMedSci(Hons) FRACS, \\ Stephen A Barnett MBBS FRACS, Louise Bentley FRANZCA, Megan A Rees PhD FRACP
}

\section{Case Report}

A 17 year-old non-smoker presented with an intractable dry cough. Previous episodes of cough had been clinically diagnosed as asthma and treated with Budesonide/Fomoterol with partial effect. She had no dyspnoea, chest pain, or fever. She was obese (BMI 33) and had no previous thoracoabdominal trauma or surgery.

Chest auscultation revealed markedly reduced breath sounds in the right middle and lower zones with bowel sounds heard in the right base. She had left sided expiratory wheeze. A chest X-ray (CXR) displayed a moderately elevated right hemidiaphragm (Figure 1a). Two years previously, a CXR revealed mild elevation of the right hemidiaphragm posteriorly. She had a normal CXR at age 3 years.

She was empirically treated for an acute asthma exacerbation with oral corticosteroids and inhaled bronchodilators. A fluoroscopic sniff test demonstrated paradoxical elevation of the right hemidiaphragm with deep inspiration suggestive of a right phrenic nerve palsy.

After admission, she became more unwell with sinus tachycardia up to $130 \mathrm{bpm}$, respiratory rate 20 breaths/minute, room air $\mathrm{SpO}_{2} 98 \%$, blood pressure 140/85 $\mathrm{mmHg}$ and she was afebrile. A computed tomography (CT) scan showed herniation of her intra-abdominal contents, including the

This is the author manuscript accepted for publication and has undergone full peer review but has not been through the copyediting, typesetting, pagination and proofreading process, which may lead to differences between this version and the Version of Record. Please cite this article as doi: $10.1111 / \mathrm{imj} .14196$

This article is protected by copyright. All rights reserved. 
right hepatic lobe, gallbladder, right and transverse colon, into the right hemithorax to the level of T2 consistent with a massive right diaphragmatic hernia (DH) (Figure 1b).

She proceeded to emergency surgery. Her intra-operative course was complicated by severe hypoxia and haemodynamic compromise on induction of general anaesthesia due to impaired venous return as well as right atrial and ventricular compression with tamponade. Laparotomy was performed with decompression of the hernia contents back into the abdomen. The right hemidiaphragm was split at the junction anteromedially between muscular and tendinous portions. The diaphragmatic defect was surgically repaired.

The patient made a complete recovery and her cough subsided. Her post-operative CXR (Figure 1c) and fluoroscopic sniff test were normal.

\section{Discussion}

A DH involves the prolapse of abdominal contents into the thoracic cavity due to a congenital or acquired diaphragmatic defect. Congenital DHs almost invariably present in infancy or early childhood and are either posterolateral (Bochdalek) or anterior-retrosternal (Morgagni) (1). Acquired DHs are most commonly traumatic (2), infrequently iatrogenic (3) (resulting from thoraco-abdominal surgery) and rarely spontaneous.

Spontaneous DHs are extremely uncommon (4) but have been reported in the setting of severe coughing or straining (5) and can be life threatening. In this patient, repeated episodes of raised intra-abdominal pressure caused by severe coughing bouts likely contributed to acute on chronic diaphragmatic attenuation and subsequent herniation of the intra-abdominal viscera into her thoracic cavity.

This article is protected by copyright. All rights reserved. 
Spontaneous DHs are difficult to diagnose as early symptoms can be absent or non-specific such as dyspnoea, chest or abdominal pain, cough and vomiting (6). Signs of cardiovascular and respiratory compromise only present in the late stage. Similarly, early imaging findings may be unremarkable or subtle.

\section{Conclusion}

Spontaneous DHs are exceedingly rare in adolescents and adults. A DH should be considered as a cause of an elevated hemidiaphragm even in the absence of prior thoraco-abdominal trauma or surgery.

Figure 1 (a) Initial CXR demonstrates a markedly raised right hemidiaphragm with a loop of large bowel visible anterior to the liver. (b) Contrast-enhanced coronal CT chest performed on day 2 of the patient's admission demonstrates a large right-sided $\mathrm{DH}$. The right lobe of the liver, the gallbladder, porta hepatis and hepatic flexure, ascending colon, caecum, distal ileum and proximal duodenum have herniated into the right hemithorax. There is compression of the right atrium and vena cava. (c) CXR performed 2 weeks post diaphragmatic hernia repair show return of the right hemidiaphragm to a normal position, re-expansion of the right lung, and only minor blunting of the right costophrenic angle.

\section{References}

1. Testini M, Girardi A, Isernia RM, De Palma A, Catalano G, Pezzolla A, et al. Emergency surgery due to diaphragmatic hernia: case series and review. World J Emerg Surg. 2017;12:23.

This article is protected by copyright. All rights reserved. 
2. Meyers BF, McCabe CJ. Traumatic diaphragmatic hernia. Occult marker of serious injury. Ann Surg. 1993;218(6):783-90.

3. Axon PR, Whatling PJ, Dwerryhouse S, Forrester-Wood CP. Strangulated iatrogenic diaphragmatic hernia: a late diagnosed complication. Eur J Cardiothorac Surg. 1995;9(11):664-6.

4. Losanoff JE, Edelman DA, Salwen WA, Basson MD. Spontaneous rupture of the diaphragm: case report and comprehensive review of the world literature. J Thorac Cardiovasc Surg. 2010;139(6):e127-8.

5. Kara E, Kaya Y, Zeybek R, Coskun T, Yavuz C. A case of a diaphragmatic rupture complicated with lacerations of stomach and spleen caused by a violent cough presenting with mediastinal shift. Ann Acad Med Singapore. 2004;33(5):649-50.

6. Rashid F, Chakrabarty MM, Singh R, Iftikhar SY. A review on delayed presentation of diaphragmatic rupture. World J Emerg Surg. 2009;4:32.

This article is protected by copyright. All rights reserved. 
Abstract:

This case report describes an extremely rare case of an adolescent patient with a history of asthma who presented to the emergency department with a worsening chronic cough and a moderately elevated right hemidiaphragm. She became acutely haemodynamically unstable due to a massive right-sided spontaneous diaphragmatic hernia.

This article is protected by copyright. All rights reserved. 


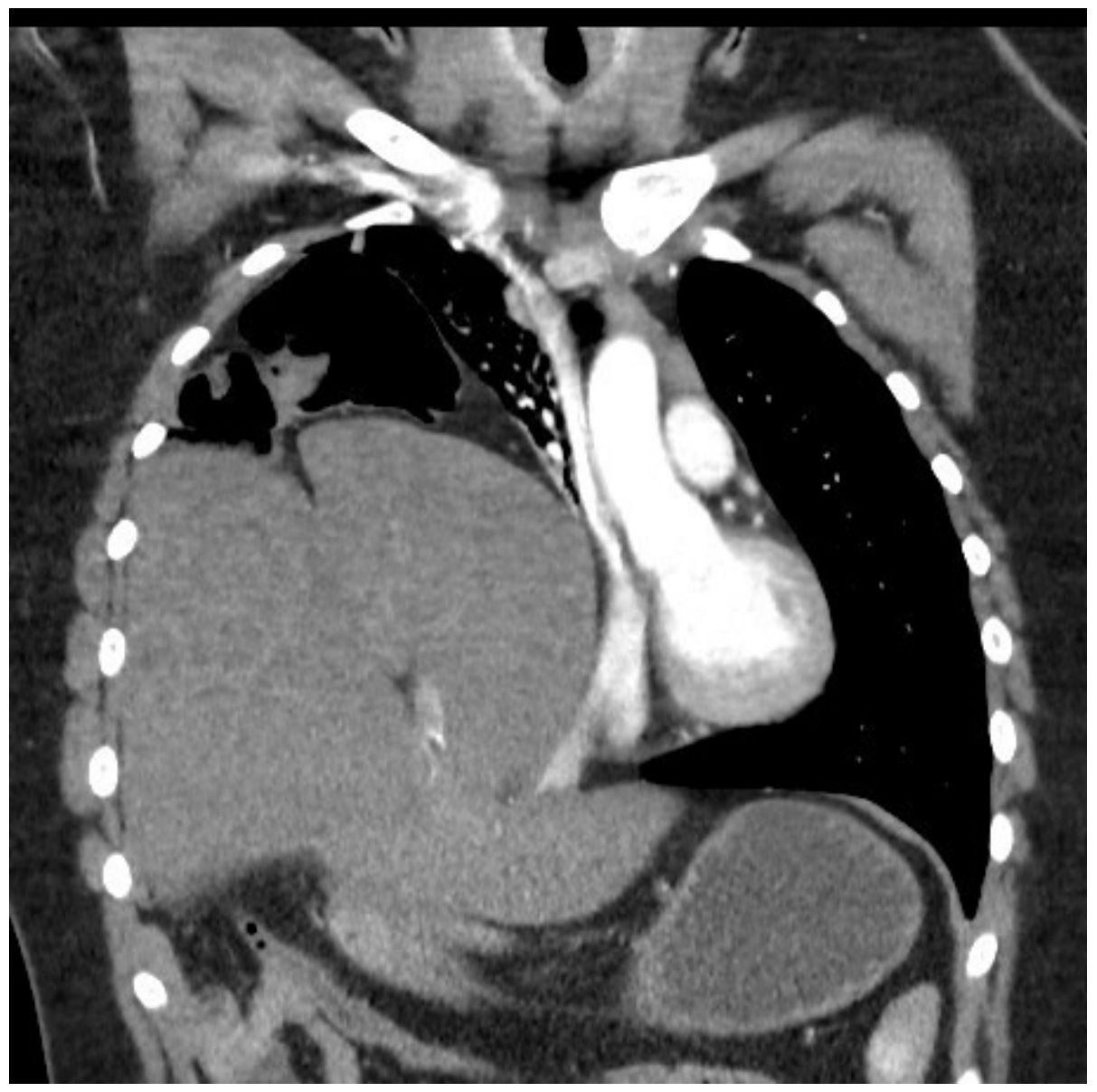

Fig1b_Pre-Op_CoronalCT.jpg

This article is protected by copyright. All rights reserved. 


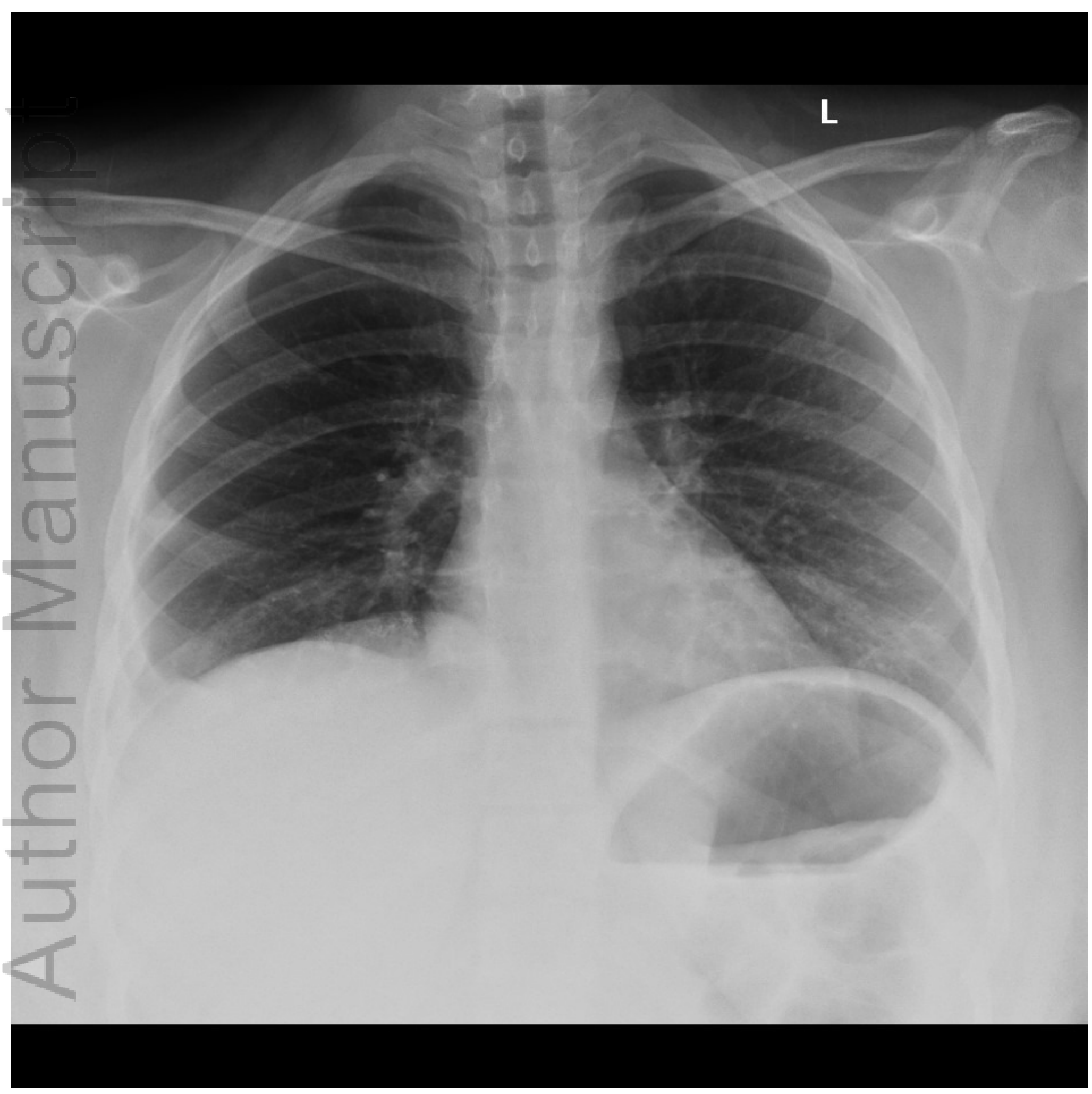

Fig1c_CXR_Postop.jpg

This article is protected by copyright. All rights reserved. 


\title{
An unusual cause of an elevated hemidiaphragm: Large right-sided spontaneous diaphragmatic hernia induced by severe chronic cough in an adolescent patient with asthma
}

\author{
Authors: \\ Margaret TH Nguyen BMedSci(Hons) MD \\ Registrar, Department of Medical Imaging, Western Health, Gordon St Footscray, Victoria, Australia.
}

Fiona SW Reid BMBS BMedSci(Hons) FRACS

Surgical Registrar, Department of Surgery, Western Health, Gordon St Footscray, Victoria, Australia.

\author{
Stephen A Barnett MBBS FRACS \\ Consultant Cardio-Thoracic Surgeon, Department of Surgery, Western Health, Gordon St Footscray, \\ Victoria, Australia.
}

Louise Bentley FRANZCA

Consultant Radiologist, Department of Medical Imaging, Western Health, Gordon St Footscray, Victoria, Australia.

\section{Megan A Rees PhD FRACP}

Consultant Respiratory Physician, Department of Respiratory Medicine and Sleep Disorders, Western Health, Gordon St Footscray, Victoria, Australia.

Tel: +61431110995

Email : megan.rees@wh.org.au

Word Count: Abstract $=47$, Manuscript $=499$

Abstract:This case report describes an extremely rare case of an adolescent patient with a history of asthma who presented to the emergency department with a worsening chronic cough and a moderately elevated right hemidiaphragm. She became acutely haemodynamically unstable due to a massive right-sided spontaneous diaphragmatic hernia.

Keywords: Elevated hemidiaphragm. Diaphragmatic hernia, Tamponade, Cough, Adolescent

This article is protected by copyright. All rights reserved. 


\section{University Library}

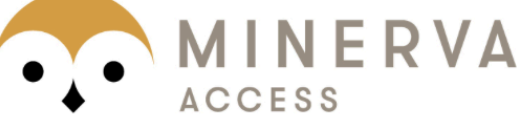

A gateway to Melbourne's research publications

Minerva Access is the Institutional Repository of The University of Melbourne

Author/s:

Nguyen, MTH;Reid, FSW;Barnett, SA;Bentley, L;Rees, MA

Title:

Unusual cause of an elevated hemidiaphragm: large right-sided spontaneous diaphragmatic hernia induced by severe chronic cough in an adolescent patient with asthma

Date:

2019-02-01

Citation:

Nguyen, M. T. H., Reid, F. S. W., Barnett, S. A., Bentley, L. \& Rees, M. A. (2019). Unusual cause of an elevated hemidiaphragm: large right-sided spontaneous diaphragmatic hernia induced by severe chronic cough in an adolescent patient with asthma. INTERNAL MEDICINE JOURNAL, 49 (2), pp.273-+. https://doi.org/10.1111/imj.14196.

Persistent Link:

http://hdl.handle.net/11343/285407 